\title{
Nanoscale Patterning in Mixed Fluorocarbon-Hydrocarbon Phospholipid Bilayers
}

\author{
Nicholas C. Yoder ${ }^{\dagger}$, Venkateshwarlu Kalsani ${ }^{\dagger}$, Steffen Schuy $§$, Reiner Vogel ${ }^{\ddagger}$, Andreas \\ Janshoff $^{\star}, \S$, and Krishna Kumar ${ }^{\star}, \dagger, \#$ \\ $\dagger$ Department of Chemistry, Tufts University, Medford MA 02155 \\ §Institute for Physical Chemistry, University of Mainz, 55128 Mainz, Germany \\ $\$$ Institute for Molecular Medicine and Cell Research, University of Freiburg, 79104 Freiburg, Germany \\ \#Cancer Center, Tufts-New England Medical Center, Boston MA 02110
}

\begin{abstract}
A growing body of literature suggests that fluorocarbons can direct self-assembly within hydrocarbon environments. We report here the fabrication and characterization of supported lipid bilayers (SLBs) composed of 1,2-dipalmitoyl-sn-glycero-3-phosphocholine (DPPC) and a synthetic, fluorocarbonfunctionalized analog, 1. AFM investigation of these model membranes reveals an intricate, composition-dependent domain structure consisting of $\sim 50 \mathrm{~nm}$ stripes interspersed between $\sim 1 \mu \mathrm{m}$ sized domains. Although DSC of 1 showed a phase transition near room temperature, DSC of DPPC: 1 mixtures exhibited complex phase behavior suggesting domain segregation. Finally, temperaturedependent AFM of DPPC: 1 bilayers shows that, while the stripe structures can be melted above the $T_{\mathrm{m}}$ of $\mathbf{1}$, the stripes and domains result from immiscibility of the hydrocarbon and fluorocarbon lipid gel phases. Fluorination appears to be a promising strategy for chemical self-assembly in two dimensions. In particular, because no modification is made to the lipid headgroups, it may be useful for nanopatterning biologically relevant ligands on bilayers in vitro or in living cells.
\end{abstract}

\section{Keywords}

Lipid bilayers; self-assembly; fluorine; atomic force microscopy

\section{Introduction}

Biological systems rely on phospholipids to confine and compartmentalize essential chemical components - literally defining the cell. Phospholipids can also be used to fabricate model membranes such as vesicles and supported bilayers, which have proved useful for cell biology ${ }^{1 \mathrm{a}-\mathrm{c}}$, sensors ${ }^{1 \mathrm{~d}, \mathrm{e}}$, drug delivery ${ }^{1 \mathrm{f}}$, and novel therapies. ${ }^{1 \mathrm{~g}}$ High resolution structural techniques have been utilized to examine model membranes ${ }^{2}$, and have revealed the segregation of phospholipid bilayers into domains of distinct chemical composition. ${ }^{3}$ Similar aggregates within cell membranes are believed to play an important role in cellular signalling ${ }^{4 a}$, although direct evidence of so-called 'raft' formation in living cells remains inconclusive. $4 \mathrm{~b}$

Phospholipids are prototypical amphiphiles which combine polar and long-chain hydrocarbon functionalities to favor the formation of lamellar aggregates under physiological conditions.

*Corresponding authors: E-mail: krishna.kumar@tufts.edu; janshoff@uni-mainz.de. 
Weak attractive forces between bilayer-bound lipid molecules can segregate them into twodimensional clusters of distinct chemical composition. The physical principles governing the size and dynamic behavior of domains in a bilayer of any given composition are as yet poorly understood, but the current interest in lipid technology suggests that control over lipid selfassembly would be useful.

Fluorocarbons have unusual noncovalent aggregation properties which are suited to selfassembly in membranes. ${ }^{5}$ They are uncharged and do not participate in meaningful hydrogen bonding interactions, and they are extremely hydrophobic but only weakly interact with hydrocarbons. Our laboratory, and others, have extensively studied fluorinated peptides 6 and showed that fluorocarbon side chains can direct the oligomerization of de novo designed peptides within membranes. ${ }^{7}$ In fact segregation of hydrocarbon and fluorocarbon amphiphiles was first reported by Ringsdorf ${ }^{8 a}, \mathrm{~b}$ and Kunitake $8 \mathrm{c}$ almost 25 years ago. Since then, research on these materials has continued intermittently. Riess and co-workers synthesized many fluorinated amphiphiles, including phospholipids, which they found form vesicles of unprecedented durability. ${ }^{9}$ However, they did not explore detailed self-assembly of these compounds within hydrocarbon matrices.

More recently, Webb et al. have provided additional evidence that simple single-chain fluorinated amphiphiles aggregate within phospholipid vesicles, and used this property to study how aggregation affects molecular recognition between apposing vesicular bilayers. ${ }^{10}$ Schmidt, Tanaka and co-workers have extensively studied fluorinated glycolipid analogs based on a glycerol diether core. ${ }^{11}$ Although these compounds form domains in phospholipid bilayers, their self-assembly properties depend strongly on the saccharide headgroup.

As part of our research into interfacing fluorocarbon self-assembly with biomolecules, we have recently initiated a study on fluorocarbon phospholipids. Our goals include a deeper understanding of the relationship between fluorocarbon substitution and morphology in selfassembled systems. The patterned display of biological ligands is believed to modulate cell adhesion and signalling ${ }^{12}$, and modified lipid bilayers have proved useful for studying cell adhesion and cell-cell interactions. ${ }^{1 \mathrm{a}-\mathrm{c}}$ Surfaces displaying phosphocholine headgroups resist non-specific cell adhesion ${ }^{13}$, making these materials promising candidates for studying cellsurface interactions. ${ }^{14}$ Fluorocarbon-directed self-assembly may provide a convenient route to nanoscale patterning of biological ligands, which can currently be produced only by laborintensive polymer-based techniques. 15

In order to directly study the relationship between bilayer morphology and fluorocarbon incorporation, we have examined supported lipid bilayers of hydrocarbon and fluorocarbon phospholipids using atomic force microscopy (AFM). ${ }^{2 \mathrm{a}}$ Supported bilayers are conveniently fabricated and, because the lipid molecules are free to laterally diffuse within each leaflet, their structure reflects the self-assembly of their component molecules. ${ }^{16}$ We detail here the phase behavior and nanoscale self-assembly of bilayers composed of compound $\mathbf{1}$ combined with its all-hydrocarbon congener, dipalmitoylphosphatidylcholine (DPPC). Despite their similar structures and close phase transition temperatures, these lipids exhibit an unusual phase separation behavior unprecedented in hydrocarbon lipids. Most notably, they form complex nanoscale stripes while both lipids are in the gel phase. These stripes are distinct from previously reported rippled bilayers, and can be thermally annealed resulting in clusters of parallel, regularly spaced stripes. 


\section{Experimental Section}

\section{Materials}

DPPC was obtained from Avanti Polar Lipids (Alabaster, AL) and used without further purification. Compound 1 was synthesized according to Scheme 1. Synthetic details and characterization are included in the Supporting Information.

\section{Differential Scanning Calorimetry}

Stock solutions of lipids in $\mathrm{CHCl}_{3}$ were combined to give $1.2 \mathrm{mg}$ of lipid at the desired mole ratio and then evaporated at $65^{\circ} \mathrm{C}$ under a stream of Ar. The resulting lipid film was then dried further by rotary evaporation for $>1$ hour at $65^{\circ} \mathrm{C}$, then hydrated to final concentration of 1.9 $\mathrm{mg} / \mathrm{mL}$ in standard buffer $(10 \mathrm{mM}$ Tris- $\mathrm{HCl} \mathrm{pH} \mathrm{7.5,} 100 \mathrm{mM} \mathrm{NaCl})$ followed by repeated heating and bath sonication for 3 minutes resulting in a cloudy suspension. The multilamellar vesicle (MLV) suspensions thus obtained were loaded into a NanoDSC-II (Model 6100, Calorimetry Sciences Corporation, Provo, UT) and scanned at $1{ }^{\circ} \mathrm{C} /$ minute from $0-90{ }^{\circ} \mathrm{C}$.

\section{Supported Lipid Bilayer Fabrication}

Cloudy suspensions of DPPC:1 mixtures were prepared as above except at $1 \mathrm{mg} / \mathrm{mL}$ concentration and extruded 29 times through membranes with $100 \mathrm{~nm}$ pore size using an Avanti Mini Extruder. The resulting suspension was clear, suggesting the formation of unilamellar vesicles. Supported lipid bilayers (SLBs) were fabricated on freshly cleaved mica strips (Ted Pella, Redding, CA) held in a custom-built Teflon sample-holder by depositing $40 \mu \mathrm{L}$ of the extruded suspension with $200 \mu \mathrm{L}$ of standard buffer and $2 \mu \mathrm{L}$ of $1 \mathrm{M} \mathrm{CaCl}_{2}$. Samples were incubated at room temperature for $\sim 2$ hours, heated at $65^{\circ} \mathrm{C}$ for 10 minutes, then allowed to cool before rinsing and imaging.

\section{Atomic Force Microscopy}

AFM was performed in aqueous solutions using a Nanoscope IIIa (Digital Instruments/Veeco, Santa Barbara CA), equipped with a fluid cell, and using a silicon nitride cantilever (Olympus OTR8, Asylum Research, Santa Barbara, CA) with a nominal spring constant of $0.61 \mathrm{~N} / \mathrm{m}$. The engaged amplitude was maintained at no lower than $70 \%$ of the estimated free force amplitude to minimize sample deformation and increase the reliability of phase imaging. ${ }^{17}$ Images were flattened and processed using SPIP (Image Metrology A/S, Lyngby, Denmark).

\section{Temperature-Controlled AFM}

Experiments were carried out in aqueous solutions using a commercial scanning force microscope (Dimension 3100 with Nanoscope IIIa+A/D controller, Veeco Digital Instruments, Santa Barbara, CA) equipped with a home-built temperature stage allowing control over the temperature between $5-60^{\circ} \mathrm{C}$. Silicon nitride cantilevers (OMCL-TR400PSA, Olympus, Japan), exhibiting nominal spring constants of $0.08 \mathrm{~N} / \mathrm{m}$ were used for tapping mode in aqueous solution. ${ }^{18}$

\section{Results and Discussion}

Compound 1 (Scheme 1) is an analog of DPPC in which the terminal $n$-hexyl group of the acyl chain has been replaced with a $n$-perfluorohexyl group. The design of $\mathbf{1}$ was intended to minimize the confounding effects of headgroup differences, acyl chain length mismatch and phase behavior to examine domain formation due to fluorination. Riess et al. had previously synthesized phospholipids with similar architecture to $\mathbf{1}$, and, based on their reports we expected 1 to form lamellar phases ${ }^{19}$ and exhibit a main phase transition temperature near 35$45^{\circ} \mathrm{C}$ (vide infra). 
The synthesis of $\mathbf{1}$ exploited established procedures in fluorine and lipid chemistry and is outlined in Scheme 1. Briefly, the necessary fatty acid was prepared by radical-mediated coupling of a fluorocarbon iodide with a terminal alkenoic acid followed by dehalogenation with $\mathrm{Zn}$ dust in acid. ${ }^{20}$ Purification at this stage was abetted by the use of a fluorous phase silica gel column. ${ }^{21}$ The fatty acid was then used to acylate the commercially available $s n$ glycero-3-phosphocholine-Cd ${ }^{2+}$ complex. ${ }^{22}$ The final product was a white amorphous solid, characterized by TLC, ESI-MS, ${ }^{19} \mathrm{~F}-,{ }^{31} \mathrm{P}-,{ }^{13} \mathrm{C}$ - and ${ }^{1} \mathrm{H}-\mathrm{NMR}$ (details are included in the Supporting Information).

Morphology and material properties of lipid bilayers are strongly affected by their phase behavior, therefore we extensively examined the thermotropic phase behavior of bilayers formed from DPPC and $\mathbf{1} .^{23}$ Differential scanning calorimetry (DSC) of pure $\mathbf{1}$ revealed a weak phase transition with a main peak at $25^{\circ} \mathrm{C}$, in contrast to the sharp transition at $T_{\mathrm{m}}=41.5$ ${ }^{\circ} \mathrm{C}$ exhibited by DPPC (Figure 1). This is generally in accordance with the observations made by Riess and co-workers, who studied a series of closely related semifluorinated diacylphosphatidylcholines. They reported that short $\left(\mathrm{C}_{4}\right)$ perfluorocarbon chains could decrease $T_{\mathrm{m}}$ and long $\left(\mathrm{C}_{8}\right)$ perfluorocarbon chains could increase it relative to the allhydrocarbon system, $9 \mathrm{~b}, 19$ although for their compounds $\mathrm{C}_{6}$ perfluorocarbon substitutions had little effect on $T_{\mathrm{m}}$. In the same studies they also found that fluorocarbon substitution drastically decreased the enthalpy of phase transition, which they attributed to the conformationally rigidifying effect of the perfluorocarbon spacer. ${ }^{24}$

DSC of various mixtures of DPPC and 1 showed complex phase behavior. In all cases, 3-4 peaks were observed, but assignment to any particular phase transition was difficult. The lone exception is the main transition of DPPC, which consistently appeared at $37-40{ }^{\circ} \mathrm{C}$. Addition of 50 mole $\%$ of 1 resulted in only a slight broadening of this transition, indicating minimal interaction between the two phospholipids (not shown). The appearance of at least three peaks presumably corresponds to the three peaks shown in the DSC traces of pure DPPC and $\mathbf{1}$ (i.e., main transition and pretransition ${ }^{23}$ in DPPC, and a main transition in 1) (Figure 1). This is also consistent with segregation of the bilayer into microscopic domains which undergo phase transitions independently of each other. ${ }^{3}$ In brief, DSC of 1 and its mixtures with DPPC shows phase behavior consistent with prior literature reports and are indicative of phase separation in all binary mixtures.

Mixtures of DPPC and $\mathbf{1}$ can be used to fabricate supported lipid bilayers using gentle hydration, extrusion and incubation as described, suggesting they readily form vesicular suspensions in aqueous media. While pure DPPC SLBs fabricated by this method appeared uniformly flat by AFM analysis, incorporation of fluorinated lipid $\mathbf{1}$ lead to drastic changes in bilayer morphology (Figure 2). The maximum thickness of the bilayer (as measured from defect edges) remained $5 \mathrm{~nm}$, but domains lower by an average of $1.2 \mathrm{~nm}$ appeared in all samples incorporating $\mathbf{1}$. More remarkably, these bilayers also exhibited narrow indentations with a striking, quasi-ordered morphology, which we refer to as 'stripes'. Precise measurement of the stripe depth is difficult due to the finite tip size and instrument noise, but appears to average $0.4 \mathrm{~nm}$.

Increasing the mole fraction of $\mathbf{1}$ from $15 \%$ to $75 \%$ completely altered the bilayer morphology (Figure 2). The area of the low domains increased until, at $75 \% 1$, the surface appeared as a bilayer with protruding domains (with thickness matching pure DPPC bilayers). Stripe morphology showed a more complex change with composition. At $15 \% 1$, the domains were elongated and stripes protruded from them in short, parallel clusters about $40 \mathrm{~nm}$ apart. With the composition at 35\% 1, almost the entire high surface area was covered in long, parallel stripes with similar spacing. At 55\% 1, the stripes were no longer arranged parallel to each 
other, and at $75 \% 1$ the stripes adopted a reticulated pattern, breaking the high domains into rounded spots $\sim 50-100 \mathrm{~nm}$ across.

Bilayers with a rippled appearance have been observed previously in pure DPPC SLBs, with this morphology attributed to high $(>50 \mathrm{mM})$ concentrations of Tris-based buffers. ${ }^{25}$ However, we observed essentially identical bilayer morphology under various buffer conditions and no ripples in pure DPPC bilayers despite the presence of $10 \mathrm{mM}$ Tris (see Supporting Information).

Rippled bilayers have also long been observed in multi-bilayer systems near phase transitions, and are attributed to the formation of a $\mathrm{P} \beta^{\prime}$ or ripple phase intermediate between the gel and liquid phases. ${ }^{26}$ Although our system fabricates single bilayers, and the morphology of $\mathrm{P} \beta{ }^{\prime}$ ripples is distinct from those we observed in DPPC:1 SLBs, we carried out variable-temperature AFM in order to further probe the mechanism of domain and stripe formation as a function of temperature and phase state of the lipids.

Initial variable-temperature AFM experiments on DPPC:1 SLBs showed that at temperatures above the main transition of $\mathbf{1}$, no stripes are observed (Figure 3 ). The bilayer exhibited a globular domain morphology similar to other gel-liquid phase-separated bilayers. ${ }^{27}$ The height difference between the two phases remained approximately $1.1 \mathrm{~nm}$. Time-lapse imaging at 32 ${ }^{\circ} \mathrm{C}$ revealed that the higher domains, presumably composed primarily of DPPC, occasionally extended laterally and fused with each other. Continuous scanning of the surface with the AFM with reasonable loading (free amplitude damping $\mathrm{A} / \mathrm{A}_{0} \sim 0.7$ ) at this temperature can also melt the DPPC-enriched domains (Figure 3). These observations suggest that, at temperatures above its main phase transition, bilayers largely composed of $\mathbf{1}$ melt into a conventional fluid phase. The DPPC-rich areas remain in the gel phase, forming bilayer domains of ordinary thickness.

Next we studied the nanoscale structure of DPPC:1 SLBs at low temperatures. AFM at $8{ }^{\circ} \mathrm{C}$ shows that both domains and stripes remained at this temperature (Figure 4A), and are thus at least metastable well below the main phase transition of $\mathbf{1}$. Furthermore, we discovered that stripes in gel phase DPPC:1 bilayers can be realigned via an annealing process previously unobserved in lipid bilayers. The SLB shown in Figure 4B was first prepared using the standard method, then held at $60^{\circ} \mathrm{C}$ for 20 minutes, well above the phase transition temperature of both bilayer components. The sample was then quenched over 30 minutes to $16^{\circ} \mathrm{C}$, followed by imaging for 30 minutes at $16^{\circ} \mathrm{C}$. This process realigns the high DPPC domains into a more ordered arrangement of long, parallel stripes regularly separated by narrow grooves and surrounded by low domains presumably composed of $\mathbf{1}$. In phase separated bilayers of ordinary hydrocarbon phospholipids, domain size can be altered by heating the bilayer to a completely fluid state and then varying the quenching rate, with a slower quench giving larger domains. 28 However, a globular morphology is invariably observed, 27,29 in contrast to the present case which shows a largely periodic stripe spacing of approximately $35 \mathrm{~nm}$. High resolution imaging (Figure 4C) of this sample also revealed tiny, dendritic stripes in between the major stripes. The apparent height of these stripes was slightly lower than the major stripes $(0.9 \mathrm{~nm})$, but this is likely an artifact of the finite AFM tip size. Finally, we note that over the time course of this experiment, the overall morphology and step height of the ripples and domains was preserved. We conclude that the domains and stripes are intrinsic features of the two gel phases of DPPC and 1. Although heterogeneity in gel phase lipids is not unexpected, we can find no previously reported examples of this phenomenon. Particularly remarkable is that the two lipids have identical headgroups and similar acyl chains, and show a $T_{\mathrm{m}}$ difference of only $16.5^{\circ} \mathrm{C}$.

Although the AFM does not give an unambiguous map of the chemical distribution of lipid species in the bilayer, the aggregate evidence strongly suggests that the high areas are composed mostly of DPPC and the low areas are composed mostly of $\mathbf{1}$. This hypothesis is also supported by AFM phase imaging of DPPC:1 bilayers (Figure 4C). Phase imaging maps the stiffness of 
the surface at a given point by measuring the degree of phase damping introduced by the tipsurface interaction. Both DPPC and $\mathbf{1}$ are apparently in the gel phase at $16^{\circ} \mathrm{C}$, and thus are expected to show similar mechanical properties. However, significant contrast was observed in phase images of DPPC: 1 bilayers. The phase image in Figure $4 \mathrm{C}$ showed a lag value of $+1.2^{\circ}$ between the lower (presumed to be 1) and higher domains (DPPC). By comparison, measurement at defect sites (not shown) showed a phase lag of $1.4^{\circ}$ between DPPC and the rigid mica surface. Riess et al. ${ }^{19}$ had previously suggested a rigidifying effect of the fluorocarbon segments in semifluorinated phospholipids, and our results are consistent with bilayers of $\mathbf{1}$ showing higher stiffness than their hydrocarbon counterparts.

The cumulative evidence suggests, again, that in the gel phase DPPC is not miscible with its fluorocarbon congener 1 but instead forms micro- and nanoscale phase-separated bilayers (Figure 2 and Figure 4). Melting of $\mathbf{1}$ results in a classical gel-liquid phase separated bilayer in which high gel domains protrude from a lower fluid phase (Figure 3).

Molecular packing in DPPC: $\mathbf{1}$ bilayers is difficult to assess by the data presented here. Indeed, it is possible that the lipid molecules adopt distinct molecular packing motifs in the domain and stripe areas. Preliminary attenuated total reflectance infrared (ATR-IR) spectroscopy 30 of oriented films of pure 1 reveals a tilt angle of $42 \pm 3^{\circ}$, compared with the angle of $21 \pm 2^{\circ}$ observed for DPPC. ${ }^{31}$ This conformational behavior is consistent with $\mathrm{x}$-ray crystallographic structures and other evidence that segmented hydrocarbon-fluorocarbon alkyl chains adopt tilt angles distinct from their parent all-hydrocarbon chains in the solid state and in self-assembled monolayers. ${ }^{32}, 33$ The difference in tilt angle between DPPC and $\mathbf{1}$ translates into an apparent difference in thickness of about $1.1 \pm 0.2 \mathrm{~nm}$, in good agreement with the domain-domain height difference observed by AFM $(1.2 \mathrm{~nm}) .{ }^{34}$ This provides additional evidence that the lower domains are enriched in $\mathbf{1}$, and suggests that conformational preferences play a large role in driving the two compounds into different domain areas despite their similar size.

Previous examples of fluorocarbon-hydrocarbon segregation have been ascribed to differences in intermolecular dispersion forces. ${ }^{32}$ These effects may also affect the formation of the structures shown in DPPC: 1 bilayers. We note that the bilayer stripe patterns are reminiscent of 'modulated phase' systems such as ferromagnetic crystals or microphase-separated block copolymer films. ${ }^{35}$ These systems display elaborate, periodic morphologies attributed to the competition between forces favoring mixing and segregation. Such a model was recently advanced to describe the stripes observed in a Langmuir monolayer of a pure fluorinated amphiphile by fluorescence microscopy. ${ }^{36}$ In the present case we observe a mixed fluorocarbon-hydrocarbon system which gives rise to both microscale domains and nanoscale stripes, as opposed to the $2-8 \mu \mathrm{m}$ stripes observed by Tanaka et al. ${ }^{36}$ We speculate that DPPC and 1 may form distinct regions of strict phase separation (i.e. the large domain areas) and modulated phase (i.e., the stripes). Notably, the stripe morphology is surprisingly reminiscent of certain micro-phase separated block copolymers, which can also be realigned by annealing. 37

\section{Conclusions}

We have described a patterned self-assembled surface in which a chemical substitution, fluorination, drives lateral heterogeneity. Characterization of the bulk material properties with DSC, as well as the nanoscale properties using temperature-dependent AFM, allows us to explore the unusual stripe morphology observed in our mixed fluorocarbon-hydrocarbon bilayers. Furthermore, these stripes undergo an ordered realignment upon annealing, giving a fingerprint texture reminiscent of microphase-separated block copolymer films. 
In many ways this is the simplest possible application of fluorocarbon-hydrocarbon immiscibility to self-assembly. The remarkable structures obtained, at both the $100 \mathrm{~nm}$ and larger length scales, in an aqueous, inherently biocompatible ${ }^{13}$ context, suggests that this principle may be widely applicable to the design of amphiphiles for biomaterials or electronics applications. 38,39 It is also likely to be compatible with existing top-down fabrication strategies for functional thin layers. $37,40,41$

In future experiments we hope to use additional methodologies to study the distribution of molecules within the bilayer domains and stripes. ${ }^{2 b, 42}$ Synthesis and characterization of additional fluorinated phospholipids will shed light on the relationship between lipid fluorination and bilayer morphology. We also plan to apply these surface fabrication principles for the design of patterned biomaterials, and, finally, to investigate the possibility of selfassembling lipid domains within living cells. 5

\section{Supplementary Material}

Refer to Web version on PubMed Central for supplementary material.

\section{Acknowledgments}

This work was supported by the NIH and NSF. We gratefully acknowledge D. Walt and his group, in particular J. Tam and K. Brogan, for the generous use of their AFM instrument and their assistance. We thank M. Curtis for assistance with DSC. We also thank E. C. H. Sykes and A. Baber for assistance with AFM data processing, and C. Steinem for helpful discussions. Mass Spectrometry and DSC facilities at Tufts University are supported by the NSF (CHE-0320783 and DMR-0520655, respectively).

\section{References}

1. (a) Mossman KD, Campi G, Groves JT, Dustin ML. Science 2005;310:1191-1193. [PubMed: 16293763] (b) Nam JM, Nair PM, Neve RM, Gray JW, Groves JT. Chembiochem 2006;7:436-440. [PubMed: 16456901] (c) Svedhem S, Dahlborg D, Ekeroth J, Kelly J, Hook F, Gold J. Langmuir 2003;19:6730-6736. (d) Janshoff A, Steinem C. Anal. Bioanal. Chem 2006;335:433-451. [PubMed: 16598461] (e) Edwards KA, Baeumner AJ. Talanta 2006;68:1421-1431. (f) Torchilin VP. Nat. Rev. Drug Discov 2005;4:145-160. [PubMed: 15688077] (g) Rai P, Padala C, Poon V, Saraph A, Basha S, Kate S, Tao K, Mogridge J, Kane RS. Nat. Biotechnol 2006;24:582-586. [PubMed: 16633350]

2. (a) Janshoff A, Steinem C. Chembiochem 2001;2:799-808. (b) Kraft ML, Weber PK, Longo ML, Hutcheon ID, Boxer SG. Science 2006;313:1948-1951. [PubMed: 17008528] (c) Korlach J, Schwille P, Webb WW, Feigenson GW. Proc. Natl. Acad. Sci. U. S. A 1999;96:8461-8466. [PubMed: 10411897]

3. Binder WH, Barragan V, Menger FM. Angew. Chem., Int. Ed 2003;42:5802-5827.

4. (a) Simons K, Toomre D. Nat. Rev. Mol. Cell Biol 2000;1:31-39. [PubMed: 11413487] (b) Munro S. Cell 2003;115:377-388. [PubMed: 14622593]

5. Yoder NC, Yuksel D, Dafik L, Kumar K. Curr. Opin. Chem. Biol 2006;10:576-583. [PubMed: 17055332]

6. (a) Bilgicer B, Fichera A, Kumar KJ. Am. Chem. Soc 2001;123:4393-4399. (b) Bilgiçer B, Xing X, Kumar K. J. Am. Chem. Soc 2001;123:11815-11816. [PubMed: 11716746] (c) Bilgicer B, Kumar K. Tetrahedron 2002;58:4105-4112. (d) Tang Y, Ghirlanda G, Petka WA, Nakajima T, DeGrado WF, Tirrell DA. Angew. Chem., Int. Ed 2001;40:1494-1496. (e) Lee KH, Lee HY, Slutsky MM, Anderson JT, Marsh ENG. Biochemistry 2004;43:16277-16284. [PubMed: 15610021]

7. Bilgiçer B, Kumar K. Proc. Natl. Acad. Sci. U. S. A 2004;101:15324-15329. [PubMed: 15486092]

8. (a) Elbert R, Folda T, Ringsdorf H. J. Am. Chem. Soc 1984;106:7687-7692. (b) Buschl R, Folda T, Ringsdorf H. Makromol. Chem. Suppl 1984;6:245-258. (c) Kunitake T, Tawaki S, Nakashima N. Bull. Chem. Soc. Jpn 1983;56:3235-3242.

9. (a) Riess JG, Krafft MP. Chem. Phys. Lipids 1995;75:1-14. (b) Riess JG. Tetrahedron 2002;58:41134131 . 
10. (a) Webb SJ, Greenaway K, Bayati M, Trembleau L. Org. Biomol. Chem 2006;4:2399-2407. [PubMed: 16763685] (b) Mart RJ, Liem KP, Wang X, Webb SJ. J. Am. Chem. Soc 2006;128:14462_ 14463. [PubMed: 17090021]

11. (a) Gege C, Schneider MF, Schumacher G, Limozin L, Rothe U, Bendas G, Tanaka M, Schmidt RR. ChemPhysChem 2004;5:216-224. [PubMed: 15038282] (b) Schumacher G, Bakowsky U, Gege C, Schmidt RR, Rothe U, Bendas G. Biochemistry 2006;45:2894-2903. [PubMed: 16503644]

12. (a) Stevens MM, George JH. Science 2005;310:1135-1138. [PubMed: 16293749] (b) Mammen M, Choi SK, Whitesides GM. Angew. Chem., Int. Ed 1998;37:2755-2794.

13. (a) Andersson AS, Glasmastar K, Sutherland D, Lidberg U, Kasemo B. J. Biomed. Mater. Res. Part A 2003;64A:622-629. (b) Iwasaki Y, Ishihara K. Anal. Bioanal. Chem 2005;381:534-546. [PubMed: 15723256]

14. Mrksich M. Chem. Soc. Rev 2000;29:267-273.

15. (a) Maheshwari G, Brown G, Lauffenburger DA, Wells A, Griffith LG. Journal of Cell Science 2000;113:1677-1686. [PubMed: 10769199] (b) Lee KY, Alsberg E, Hsiong S, Comisar W, Linderman J, Ziff R, Mooney D. Nano Lett 2004;4:1501-1506. (c) Cavalcanti-Adam EA, Micoulet A, Blummel J, Auernheimer J, Kessler H, Spatz JP. Eur. J. Cell Biol 2006;85:219-224. [PubMed: 16546564]

16. Tamm LK, McConnell HM. Biophys. J 1985;47:105-113. [PubMed: 3978184]

17. Magonov SN, Elings V, Whangbo MH. Surf. Sci 1997;375:L385-L391.

18. Schuy S, Janshoff A. ChemPhysChem 2006;7:1207-1210. [PubMed: 16676368]

19. Santaella C, Vierling P, Riess JG, Gulikkrzywicki T, Gulik A, Monasse B. Biochim. Biophys. ActaBiomembr 1994;1190:25-39.

20. (a) Graupe M, Koini T, Wang VY, Nassif GM, Colorado R, Villazana RJ, Dong H, Miura YF, Shmakova OE, Lee TR. J. Fluorine Chem 1999;93:107-115. (b) Brace NO. J. Org. Chem 1962;27:4491-4498.

21. Curran DP. Synlett 2001;9:1488-1496.

22. (a) Menger FM, Wood MG, Richardson S, Zhou Q, Elrington AR, Sherrod MJ. J. Am. Chem. Soc 1988;110:6797-6803. (b) Singh A. J. Lipid Res 1990;31:1522-1525. [PubMed: 2280193]

23. Lewis, RNAH.; McElhaney, RN. The Structure of Biological Membranes. Yeagle, PY., editor. Boca Raton: CRC Press; 2005. p. 53-120.

24. Eaton DF, Smart BE. J. Am. Chem. Soc 1990;112:2821-2823.

25. Mou JX, Yang J, Shao ZF. Biochemistry 1994;33:4439-4443. [PubMed: 8161497]

26. (a) Kaasgaard T, Leidy C, Crowe JH, Mouritsen OG, Jorgensen K. Biophys. J 2003;85:350-360. [PubMed: 12829489] (b) Meyer HW. Biochim. Biophys. Acta 1996;1302:138-144. [PubMed: 8695663]

27. (a) Schneider J, Dufrene YF, Barger WR, Lee GU. Biophys. J 2000;79:1107-1118. [PubMed: 10920040] (b) Leonenko ZV, Finot E, Ma H, Dahms TES, Cramb DT. Biophys. J 2004;86:37833793. [PubMed: 15189874]

28. Milhiet PE, Giocondi MC, Le Grimellec C. The Scientific World Journal 2003;3:59-74.

29. Giocondi MC, Vie V, Lesniewska E, Milhiet PE, Zinke-Allmang M, Le Grimellec C. Langmuir 2001; 17:1653-1659.

30. Picard F, Buffeteau T, Desbat B, Auger M, Pezolet M. Biophys. J 1999;76:539-551. [PubMed: 9876167]

31. Schuy S, Yoder NC, Kalsani V, Kumar K, Janshoff A, Vogel R. Unpublished results.

32. Dunitz JD. Chembiochem 2004;5:614-621. [PubMed: 15122632]

33. (a) Beier P, O'Hagan D, Pearson C, Petty MC, Slawin AMZ. J. Fluorine Chem 2005;126:673-682. (b) Tamada K, Ishida T, Knoll W, Fukushima H, Colorado R, Graupe M, Shmakova OE, Lee TR. Langmuir 2001;17:1913-1921.

34. Solid-supported bilayers of pure DPPC and $\mathbf{1}$ deposited on glass further confirm this difference in height, with the step height difference of $1.2 \mathrm{~nm}$ (see Supporting information).

35. Seul M, Andelman D. Science 1995;267:476-483. [PubMed: 17788780]

36. Schneider MF, Andelman D, Tanaka M. J. Chem. Phys 2005;122:094717. [PubMed: 15836172] 
37. (a) Hahm J, Lopes WA, Jaeger HM, Sibener SJ. J. Chem. Phys 1998;109:10111-10114. (b) Sundrani D, Darling SB, Sibener SJ. Nano Lett 2004;4:273-276.

38. Silva GA, Czeisler C, Niece KL, Beniash E, Harrington DA, Kessler JA, Stupp SI. Science 2004;303:1352-1355. [PubMed: 14739465]

39. Kato T, Mizoshita N, Kishimoto K. Angew. Chem., Int. Edit 2006;45:38-68.

40. Salaita K, Amarnath A, Maspoch D, Higgins TB, Mirkin CA. J. Am. Chem. Soc 2005;127:1128311287. [PubMed: 16089456]

41. Groves JT, Boxer SG. Acc. Chem. Res 2002;35:149-157. [PubMed: 11900518]

42. Kaasgaard T, Mouritsen OG, Jorgensen K. FEBS Lett 2002;515:29-34. [PubMed: 11943189] 


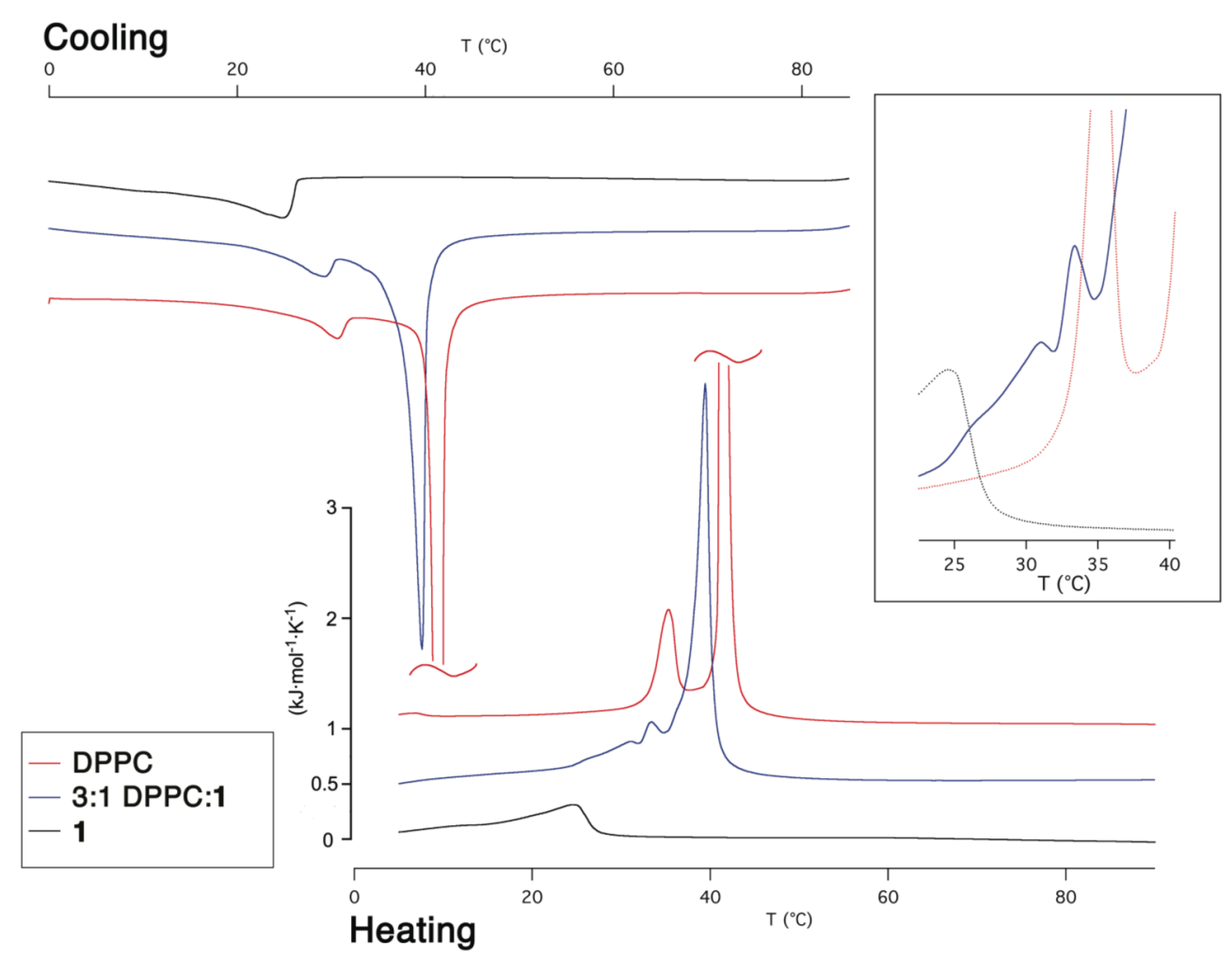

Figure 1.

DSC thermograms for pure 1 (black), DPPC (red), and a 3:1 DPPC:1 mixture (blue). Note that the main DPPC transition peak is truncated. Inset: Magnification of minor peaks in the 3:1 mixture with the pure components in the background. 

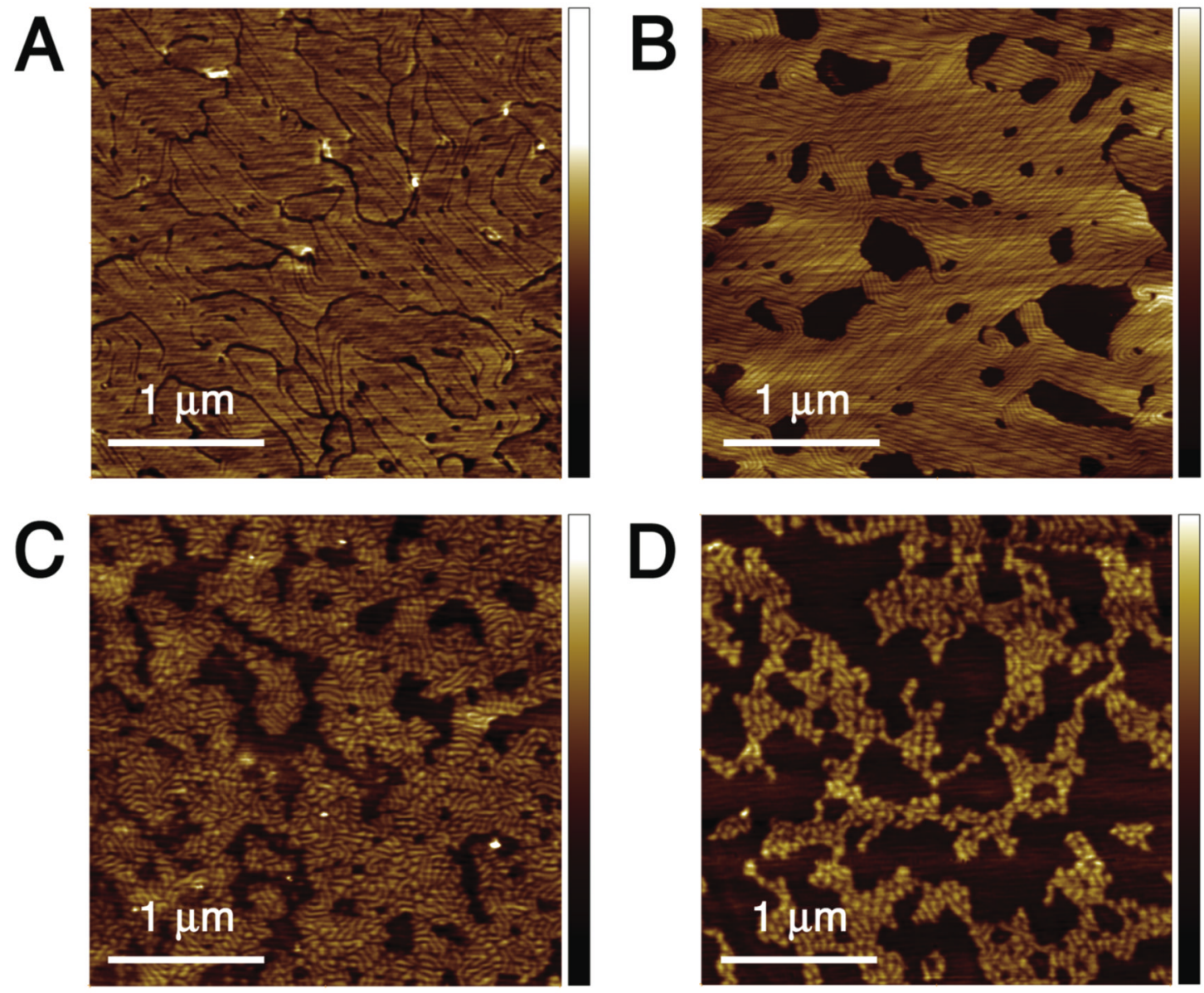

Figure 2.

AFM images of supported lipid bilayers composed of various DPPC:1 ratios: A) 85:15 (1.1 $\mathrm{nm} \mathrm{Z} \mathrm{scale);} \mathrm{B)} \mathrm{65:35} \mathrm{(2.6} \mathrm{nm} \mathrm{Z} \mathrm{scale);} \mathrm{C)} \mathrm{45:55} \mathrm{(2.1} \mathrm{nm} \mathrm{Z} \mathrm{scale);} \mathrm{D)} \mathrm{25:75} \mathrm{(2.2} \mathrm{nm} \mathrm{Z} \mathrm{scale).}$ 

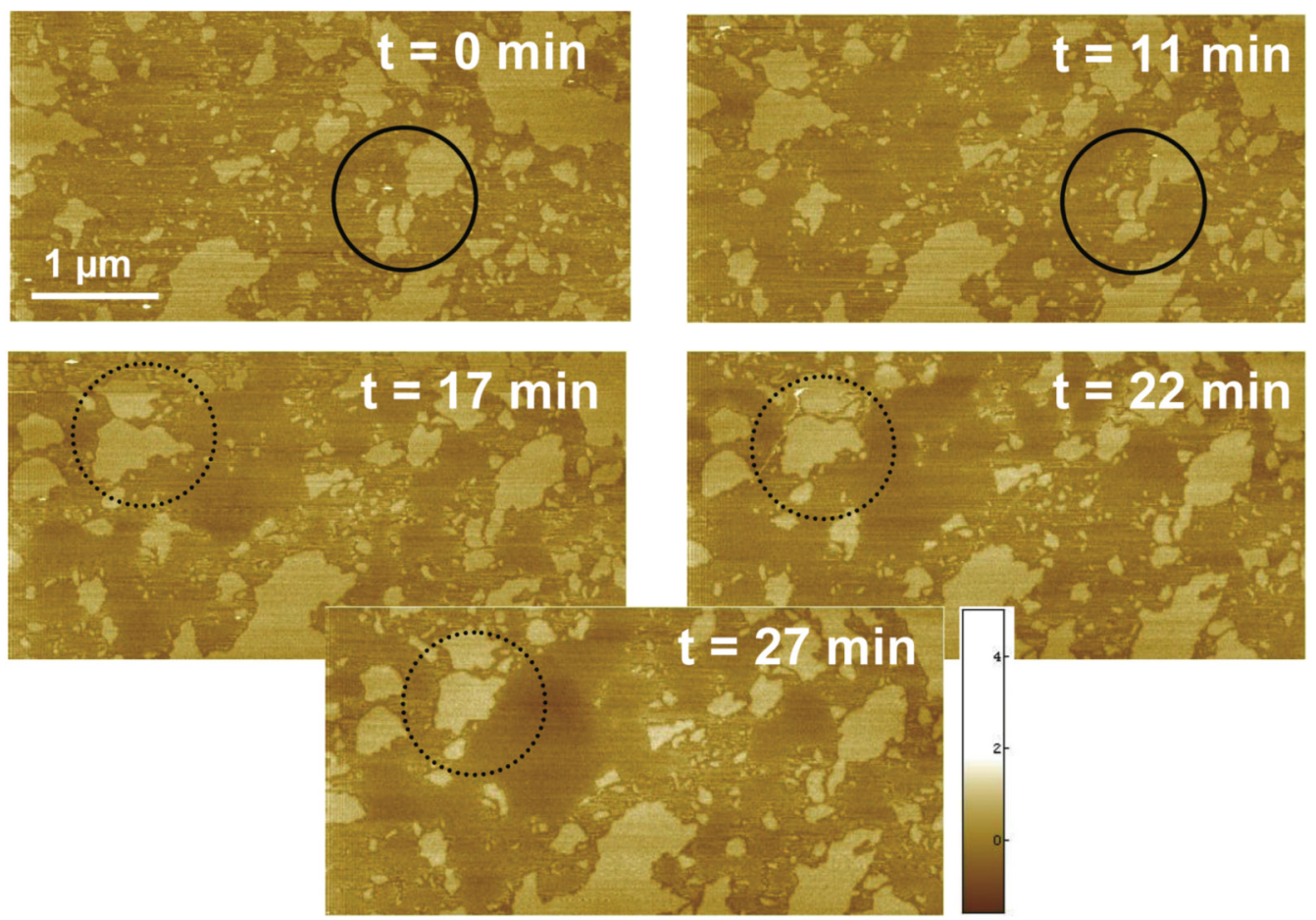

Figure 3.

Temperature dependent AFM images of SLB composed of 1:1 mixtures of DPPC:1 at $32^{\circ} \mathrm{C}$ (6.6 nm Z scale). The higher domains (lighter color) are believed to be DPPC-rich. The solid circle highlights lateral diffusion of a DPPC-rich domain fragment and its subsequent fusion with a neighbor. The dashed circle indicates the partial melting of a DPPC-rich fragment. 

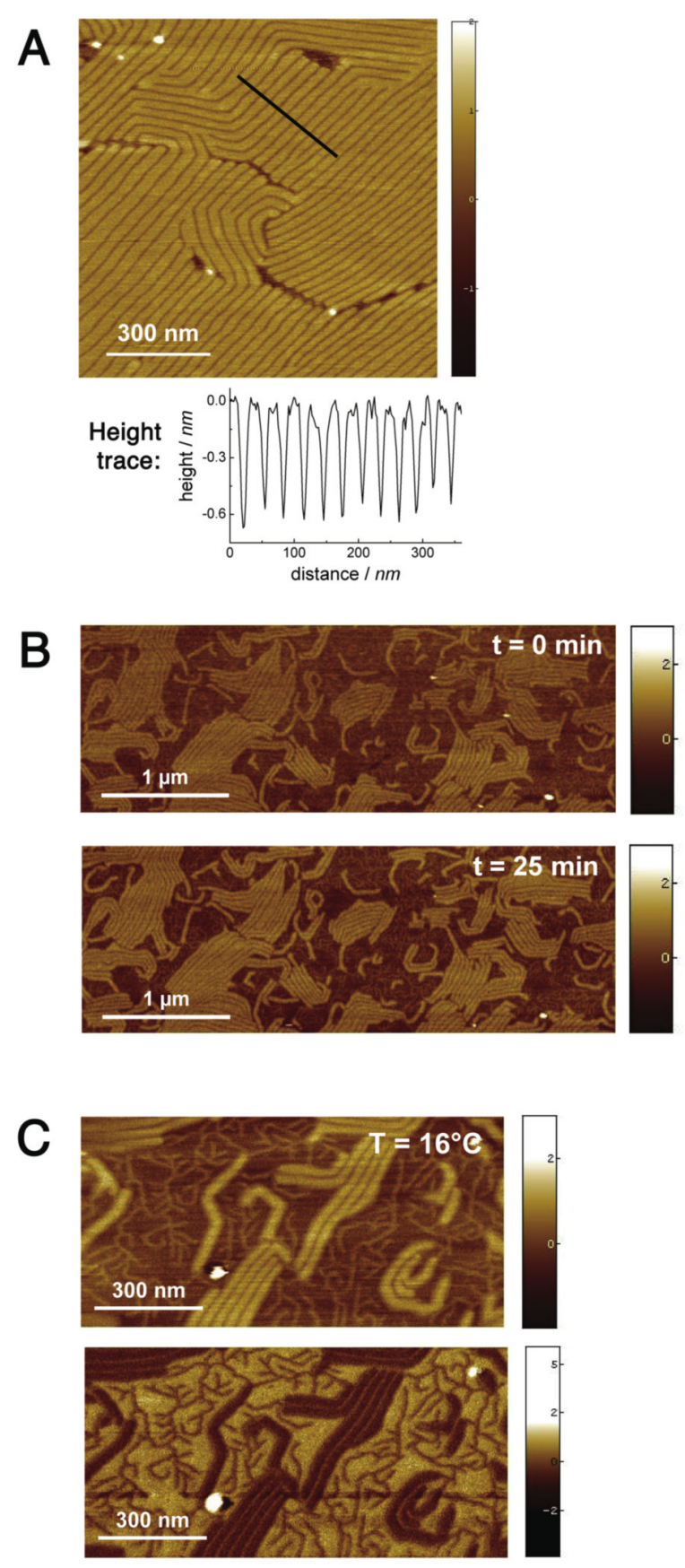

Figure 4.

Low temperature AFM of DPPC:1 SLBs. A) Detail of ripple structure in a 3:1 DPPC:1 bilayer at $8{ }^{\circ} \mathrm{C}(4 \mathrm{~nm} \mathrm{Z}$ scale). B) \& C) Time lapse scan of annealed bilayer composed of 1:1 DPPC: 1 at $16^{\circ} \mathrm{C}$. See main text for annealing procedure. B) Height images; top: 0 min. after quench to $16^{\circ} \mathrm{C}$; bottom: $25 \mathrm{~min}$. Both images are $5 \times 2.5 \mu \mathrm{m}$ (both $5 \mathrm{~nm} \mathrm{Z}$ scale). C) $1 \mu \mathrm{m} \times 0.5 \mu \mathrm{m}$ image taken at $\mathrm{t}=30 \mathrm{~min}$. after quench; top: height image; bottom: phase image. (Height image: $5 \mathrm{~nm} \mathrm{Z}$ scale; phase: $10.8^{\circ} \mathrm{Z}$ scale) 

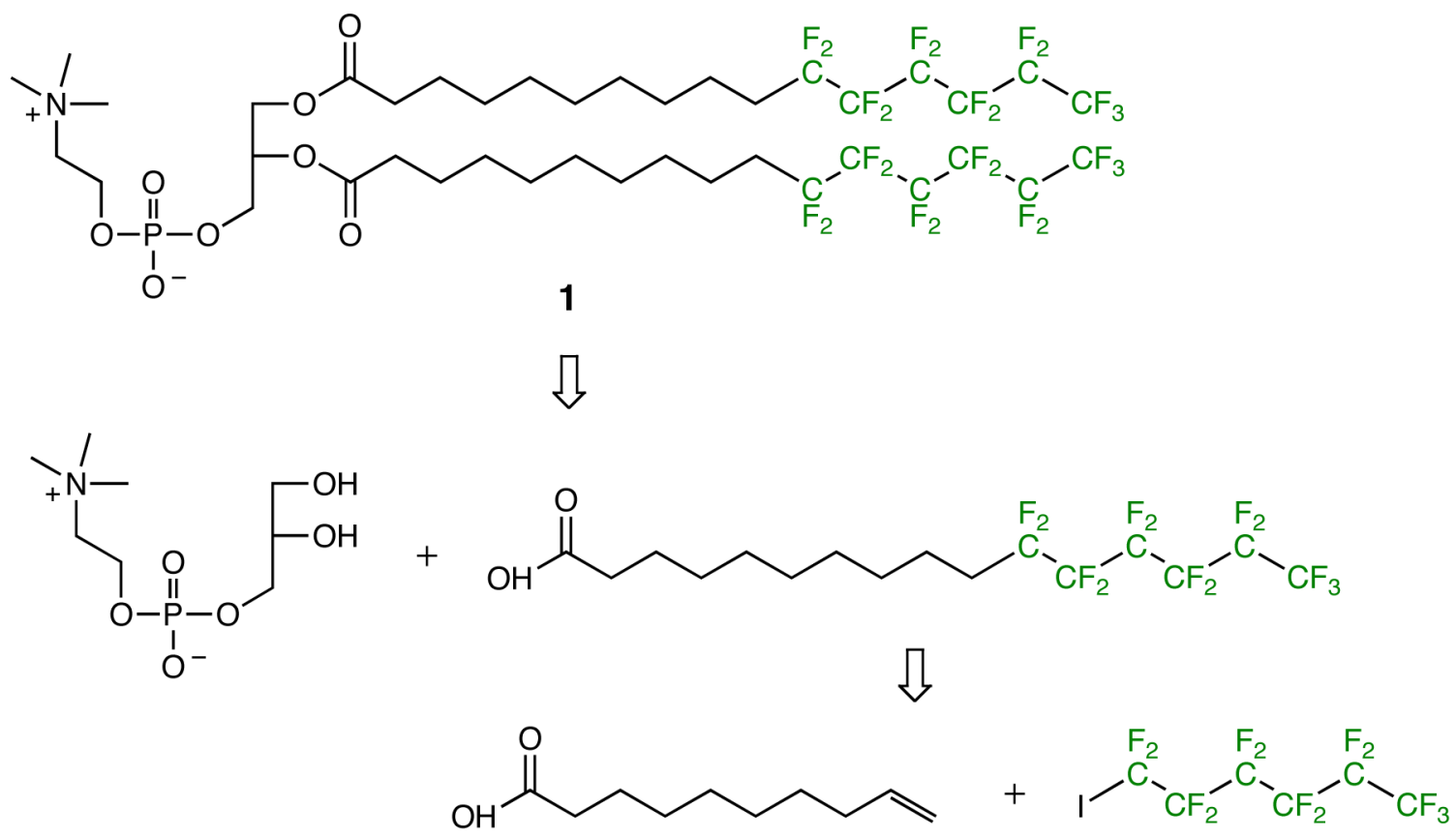

Scheme 1.

Structure and retrosynthetic analysis of $\mathbf{1}$, a fluorinated analog of DPPC. 